\title{
The Prevalence and Psychological Symptoms of Nomopho6ia among University Students
}

\author{
Dr. Salwa Ali Kateb \\ Department of Educational Psychology \\ University of Jeddah
}

Abstract:

This empirical study investigates the prevalence and symptoms of Nomophobia among university students

in Saudi Arabia. An anonymous and self-reported survey was distributed from Feb 2015 to June 2015. Out of around 1800 potential candidates, 335 undergraduate students comprised the study sample. Scores were calculated to assess demographic data and patterns of Smartphone use in terms of duration, frequency, context and purpose. Depression, Anxiety and Stress Scales (DASS) was used to assess the psychological status of the participants, and Nomophobia Questionnaire (NMP-Q) was used to assess the prevalence of Nomophobia dimensions. Statistical analysis and tests were used to identify associations among the study variables and to test the hypotheses. The findings showed that there was a high level of mobile phone involvement, high levels of the Nomophobia dimensions; females were significantly more involved than males with a mean of $3.3(S D=0.93)$ versus 2.8 $(S D=1.05)$ with a $(t=3.54, p$-value $<0.001)$. The findings also showed a "Mild" level of depression with average score was 8.55 ( Z $=0.83$ ) ( $S D=3.41$, ranging from 1 to 17), a "Normal" level of anxiety with average score was $5.96(Z=-0.03)(S D=2.9$, ranging from 0 to 12), and a "Normal" level of stress with average score was 6.55 ( $Z=-1.90$ ) ( $S D=4.8$, ranging from 0 to 18). Based on the findings, it can be concluded that the duration of use was significant with both mobile phone involvement and psychological health factors. The psychological Health factors using DASS are all correlated significantly with Mobile phone involvement factors. The findings suggest that they way a person interacts with their Smart-device, mainly duration of use, can predict the pathological fear and psychological symptoms caused by modern digital and virtual means.

Keywords: Nomophobia, Smart-devices Phobia, DASS, Social Phobia, Psychological Symptom and Factors

The Prevalence and Psychological Symptoms of Nomophobia among University Students 


\section{Highlights}

- The prevalence of Nomophobia among university students was average

- The Smartphone involvement factors were correlated significantly with psychological factors

- The high levels of Smartphone involvement and use may correlate with psychological health factors, particularly depression

- Females are more involved with Smartphone use and duration of use, and develop more psychological health factors, particularly stress

- The feelings of giving up the convenience and of disability to access information (AID) a Smartphone may correlate with psychological health factors among university students

- The duration of use and losing connectedness ware predictors for Smartphone involvement and psychological factors: depression, anxiety and stress

- The manner in which a person interacts with their Smartphone may predict the pathological fear and psychological symptoms caused by the digital and virtual influences

\section{Introduction}

The growing use of personal-oriented modern Information and Communication Technologies (ICT) such as personal computers, tablets and Smartphones is causing changes in humans' daily habits and behaviours and in the common means of perceiving reality. Being a member of the global virtual community with deep involvements has been reported to result in the development of different and novel psychological phobias (Bragazzi \& Del Puente, 2014). For example, the heavy use of the Internet caused new health and psychological concerns with negative impacts, known as Internet Addiction Syndrome (IAS). This phenomenon has been reported and treated as a psychological syndrome because adolescents with this syndrome 
may suffer from problems in their daily habits, educational performance, social interactions, and psychological health (Starcevic, 2010; Yen et al., 2008).

More recently, Nomophobia, or No Mobile Phobia, has been reported in a study to investigate the case of a patient with panic disorder and agoraphobia. The study examined the relation between Nomophobia and panic disorder and reported that the patient with a total dependence on his Smartphone received a combination of psychiatric treatment, medication, and Cognitive Behavioural Therapy (CBT); the patient's condition improved after the treatment (King, Valença, \& Nardi, 2010).Other studies reported that the interaction with new technologies including Smartphones can result in behavioural changes and may cause symptoms of Nomophobia; i.e., manifest behaviours that may be an indicator of a potential anxiety disorder or symptoms of depression mainly among young adults (King et al., 2013; Thomée, Härenstam, \& Hagberg, 2011).The dependency on virtual environments to communicate with others via the increased use of Smartphones may disable the direct social interactions among university students and other people and consequently result in static dependent behaviours or may become a mask for other problematic behaviours, sleep disturbance, poor educational performance and mental disorders (Lu et al., 2011; Yildirim, 2014).

Since smart-devices (including Smartphones, iPod, Android, Blackberry, Personal Digital Assistants (PDA), etc.) were introduced, it has been noticed that high Internet use is common on such devices. Many of those tools are now available for endusers in educational environments, mainly to interact daily with Facebook, Twitter and other social networks (Salehan \& Negahban, 2013). However, there is much evidence demonstrating that the high involvement with smart-devices via excessive phone calling, text messaging, Internet exploring, online gaming and emailing, may have positive or negative effects on the mental health of university students (e.g., Dixit et al., 2010; Yen et al., 2009; Yildirim, 2014). 
Research with a focus on Nomophobia and the pathological fear of remaining out of touch with technology has been scarce (King et al., 2013, 2014). It is important to understand why university students may immerse themselves in these smartdevice practices with high use patterns and involvement. It is also crucial to investigate the pathology of fear caused by an affliction with Nomophobia, based on the four dimensions of Nomophobia: (1) not being able to communicate, (2) losing connectedness, (3) not being able to access information and (4) giving up convenience, and then to identify the psychological symptoms associated with this phenomenon (Yildirim, 2014).Therefore, this study's objective is to determine the level of dependence and daily behavioural patterns of Smartphone use among university students in Saudi Arabia, particularly the duration, frequency, purpose and context of use. This study then attempts to identify the prevalence of Nomophobia dimensions among the target population and then to evaluate the relation between those dimensions and the status of psychological health factors: Depression, Anxiety and Stress. Those factors identify the psychological health status according to the Depression, Anxiety and Stress Scale (DASS) (Taouk, Lovibond, \& Laube, 2001). Figure 1 illustrates the research model and problem variables under investigation.

\begin{tabular}{|l|l|l|}
\hline \begin{tabular}{|l|} 
Daily Behavioral \\
Patterns of Use \\
- Duration
\end{tabular} & $\begin{array}{c}\text { Nomophobia Dimensions } \\
\text { - Not Being Able to Communicate } \\
\text { - Frequency } \\
\text { - Purpose } \\
\text { - Context }\end{array}$ \\
\hline
\end{tabular}

Figure 1: Research Model 


\section{Background}

\section{The Nomophobia Definition}

The term Nomophobia or No Mobile Phobia was first introduced as a result of a study conducted by the UK Post Office in 2008 aimed at investigating the psychological impacts of using Smartphones, particularly in terms of anxieties; the study reported that approximately two thirds of the population suffer from Nomophobia or, as described, "the fear of being without your mobile phone", i.e., the largest phobia in the world, presumably (Bivin,Mathew, Thulasi, \& Philip, 2013; Securenvoy, 2012).Thus, an individual is called a "Nomophobe" when she/he is afflicted with Nomophobia, and the term "Nomophobic" is an adjective to describe the characteristics of a Nomophobe individual and/or behaviors related to Nomophobia (Yildirim, 2014). An earlier study considered Nomophobia a 21st century disorder or syndrome caused by the use of different forms of new technologies. Nomophobia was first defined as "denotes discomfort or anxiety when out of mobile phone (MP) or computer contact. It is the fear of becoming technologically incommunicable, distant from the MP or not connected to the Web" (King et al., 2010). Other earlier work referred to Nomophobia as dependence on Smartphones (Dixit et al., 2010) or recently as an addiction syndrome to Smartphones (Forgays, Hyman, \& Schreiber, 2014).

The term is also defined as "the modern fear of being unable to communicate through a mobile phone (MP) or the Internet" (King et al., 2014). Another recent work considered Nomophobia a disorder of the contemporary digital and virtual society that may cause discomfort, anxiety, nervousness or anguish as a result of being out of contact with a Smartphone or computer (Bragazzi \& Del Puente, 2014; Yildirim, 2014).The literal meaning of "Nomophobia" as described by a recent study is also "the fear of being out of mobile phone contact" leading to a type of behavioral addiction toward using Smartphones; it 
appears as a physical dependency associated with psychological symptoms, considering that this type of addiction influences the continual use of Smartphones (Sharma et al., 2015).

Nevertheless, it can be concluded that all definitions imply that: (i) Nomophobia can be observed as a disorder involving a collection of behaviors with different clinical characteristics; (ii) Nomophobia can cause psychological symptoms and includes the pathological fear of remaining out of touch with technology; (iii) Nomophobia can be considered as a behavioral addiction that influences the continual use of Smartphones; and (iv) Nomophobia can be observed as a situational phobia related to not only the use of Smartphones but also all types of smartdevices and new technologies that enable virtual communications including personal computers, laptops, tablets, Smartphones, personal assistants, and Internet. Therefore, Nomophobia has been called the "New Technologies Paradox" (Bragazzi \& Del Puente, 2014). In this study and based on the findings of earlier studies, it can be concluded that the Nomophobia phenomenon is a behavioral disorder with psychological symptoms caused by the fear of being unable to communicate using any of the modern smart-devices and technologies for the purpose of any type of interaction.

\section{Nomophobia Epidemiology and Prevalence}

Smartphones have become so pervasive that the market of worldwide Smartphone was approximately 7 billion subscribers at the end of 2014 , i.e., an approximately $96 \%$ penetration of the worldwide population (International Telecommunication Union, 2014). As of January 2014, it has been reported that approximately $90 \%$ of the American adult population have a type of Smart-device, and approximately $58 \%$ of American adults particularly own a Smartphone. Of that 58\%:approximately $83 \%$ are aged $18-29,74 \%$ are aged $30-49,49 \%$ are aged $50-64$, and $19 \%$ are aged 65 or older (Pew Research Center, 2015). It is clear that Smartphones are more popular among young adults; university students were reported as the early adopters of Smart-devices or Smartphones (Lee, 2014). 
In recent decades, the use of Smartphones has increased, particularly in adolescents and children. The usage of Smartphones has the ability to offer several benefits. However, there are a number of problems that can be generally recognized because of the phones' usage. It is demonstrated that the problem of using Smartphones is related to extraversion, age, and low self-esteem; nevertheless, it is not related to neuroticism (Krajewska-Kułak et al., 2012). The use of Smartphones is an extremely prominent part of a number of young people's daily lives, which indicates that being the use of Smartphones has been incorporated into the self-identity of young individuals. The Smartphones' adoption as a type of self-expressive identity affects both the frequency and type of Smartphone behavior; this implies that mobile devices are considered a self-materialistic representation. Several processes emerge to have guided the mobile devices to becoming a respected element of self-identity of young people such that many young users of Smartphone cannot accept life without their mobile devices (Walsh, White, \& Mcd Young, 2010).

According to a survey conducted in the UK, approximately 13 million individuals suffer from Nomophobia, and this represents approximately 53\% of Smartphone users (58\% men and $48 \%$ women). Moreover, it was demonstrated that more women $(70 \%)$ are concerned about losing their Smartphones than men (61\%) (Bragazzi \& Del Puente, 2014). In 2008, the tendency was precisely contradictory, in that men were suffering more from this fear, with statistics indicating that $11 \%$ of men have two Smartphones compared with women. Additionally, adolescents and youngsters are more expected to acquire Nomophobia because $77 \%$ have related worries and anxiety regarding losing their Smartphones; this is followed by the age group of 25 to 34year-olds and the groups over 55 years. It has also been reported that females in general spent more time on their Smartphones compared with males in each age group, with a longer typical time for each call as well as a larger number of calls per day (Byun et al., 2013). These outcomes may confirm the likely existence of conventional gender roles within the 
mobile culture, with females indicating more concern about the communication technology's interactive side than their male counterparts do. Impaired memory and concentration are associated with each of three categories, namely the spent time on the voice call, the duration of each call, and the outgoing calls of each day (King et al., 2014). The parents' educational level is one of the factors concerning the Smartphone usage of children, with a higher Smartphone ownership rate and more rigorous use among children whose parents have lower education levels. In addition, phone ownership rates were lower in children living in rural areas than in urban areas in 2008 (Yildirim, 2014).

\section{Nomophobia Psychological Factors}

Earlier work acknowledged that young people are the most interested group in the involvement of mobile devices because this group shows high involvement compared with elder groups (Walsh, 2009). The stage of young people is considered a developmental one because they are improving their selfconcept and are extremely reliant on the approval of peers and friends to preserve their self-esteem (Bianchi, Phillips, \& Phillips, 2005). Therefore, there are a number of psychological factors addressed such as validation and self-identity from others to illustrate the effects of these factors on the Smartphone devices of young people. The attachment-related activities that evaluate involvement are associated with the behaviours' positive expectation as well as the psychological factors that inspire the behaviour's addictive patterns (Abdullah,Zulkifly, Saaid, \& Din, 2012). Moreover, it is indicated that young individuals with superior involvement with their mobile devices receive a feeling of validation from other individuals such as the feeling of being loved and valued; this demonstrates that Smartphone usage may improve the self-esteem of individuals.

Validation and self-identity are considered very important factors that affect the Smartphone behaviour of young people, whereas other factors may influence the Smartphone use of young people. Young people are greatly improving their social networks, and they are extremely reactive to normative stress 
from peers and friends (Bragazzi \& Del Puente, 2014). Consequently, social effects, such as the norms of a referent group, may affect the Smartphone usage of young people. In addition, validation from other individuals is a very significant factor for predicting Smartphone involvement, which proposes that individuals for whom support from other individuals is significant have enhanced dependence on Smartphones (Dickson, 2012).

There is a great interest in determining the psychological factors that affect Smartphone use because it has enormous clinical relevance; these factors are strongly exploited for broadcasting and for both prognosis and diagnosis. The psychological factors challenging mobile usage may be selfefficacy, low esteem, self-negative views, a younger age, for instance, in high introversion and extroversion (Bianchi et al., 2005). When urgently pursuing the overuse of Smartphones, other psychological factors appear and influence behavioural disorders involving drug consumption, alcohol, smoking, selfesteem, adjustment abilities, social skills, emotional intelligence (affective status' self-regulation), and personality (Walsh et al., 2010).

\section{Psychiatric diseases and gold standards}

The Diagnostic and Statistical Manual of Mental Disorders (DSM) is the worldwide gold standard manual to assess psychiatric diseases; DSM-4 version was in use until May 2013, at which time the fifth version DSM-5was released. According to the original DSM, a specific phobia is defined as an anxiety disorder that represents an unreasonable and irrational fear prompted by a specific stimulus; this could be an object or a situation. Although the third version used the term "simple phobia", in the fourth version, the name was changed to "specific phobia" to include five types of specific phobia: Blood/Injection/Injury (B-I-I), animal, natural environment, situational, and other (Bragazzi \& Del Puente, 2014; King \& Delfabbro, 2013). However, the DSM-5 Anxiety Work Group has 
proffered recommendations with further developments to change the criteria for diagnosing specific phobias; this mainly occurs in the technology-related phobias debate. The DSM-5 Task Force and Work Groups proposed that Internet use can be considered as a disorder in certain cases and should be included in Section 3 of the DSM-5 (King \& Delfabbro, 2013). This proposal was intended to provide further clarity to the clinical formulation of internet-related disorders or phobias.

As described in the DSM-4, situational phobia is a specific phobia and may be experienced when a specific situation causes an intense, irrational fear of a specific object or situation that leads to an intense reaction that can be both physical and emotional (Choy, Fyer, \& Lipsitz, 2007). Recently and based on comprehensive reviews and discussions of the clinical relevance of Nomophobia pathology, its epidemiological features, the available psychometric scales, and the proposed treatment, the inclusion of Nomophobia as a situational phobia in the DSM-5 has been proposed for consideration (Bragazzi \& Del Puente, 2014). It has also been explained that, in case of individuals with Nomophobia, a Nomophobe would have an irrational fear of being out of Smartphone contact or not being able to use their devices; thus, they attempt to eliminate the chances of not being able to use their Smartphone. In other words, when Nomophobes are unable to use Smart-devices, they have intense feelings of anxiety and distress (Yildirim, 2014).

Despite the latest version of the Diagnostic and Statistical Manual of Mental Disorders (DSM-5) recognizes some disorders associated with the new technologies such as Internet Gaming, Nomophobia still has no status in the DSM-5. While the exclusion of Smartphone addiction from the DSM-5 explains that this addiction is not a legitimate mental disorder, there is a growing body of evidence suggesting otherwise and indicating that compulsive Smartphone use is growing and may become a mental health problem, particularly among adolescent users (Bragazzi \& Del Puente, 2014; King \& Delfabbro, 2013). The absence of a clear definition and a measure for Smartphone 
addiction hampers research on the prevalence of this type of disordered behaviour, thereby obstructing vital next steps in the research field of Smartphone addiction.

\section{Psychometric Smartphone Scales}

Table 1. Psychometric scales for mobile phone involvement problems.

\begin{tabular}{|c|c|c|c|c|}
\hline Scale & Abbreviation & Reference & Focus & Origin \\
\hline $\begin{array}{c}\text { Mobile Phone } \\
\text { Use } \\
\text { Questionnaire }\end{array}$ & MP-UQ & $\begin{array}{l}\text { King et al. } \\
\text { (2014) }\end{array}$ & $\begin{array}{c}\text { Problematic } \\
\text { Use }\end{array}$ & Literature \\
\hline $\begin{array}{l}\text { Problematic } \\
\text { Use of Mobile } \\
\text { Phones Scale }\end{array}$ & PUMP & $\begin{array}{c}\text { Merlo, Stone, } \\
\text { and } \\
\text { Bibbey(2013) }\end{array}$ & $\begin{array}{c}\text { Problematic } \\
\text { Use }\end{array}$ & $\begin{array}{l}\text { Exploratory } \\
\text { and DSM-5 }\end{array}$ \\
\hline $\begin{array}{c}\text { Test of Mobile } \\
\text { Phone } \\
\text { Dependence }\end{array}$ & TMPD & Chóliz (2012) & Dependency & DSM-5 \\
\hline $\begin{array}{l}\text { Mobile Phone } \\
\text { Dependence } \\
\text { Questionnaire }\end{array}$ & MPDQ & $\begin{array}{l}\text { Toda et al. } \\
(2006)\end{array}$ & Dependency & Literature \\
\hline $\begin{array}{c}\text { Problematic } \\
\text { Mobile Phone } \\
\text { Use } \\
\text { Questionnaire }\end{array}$ & PMPUQ & $\begin{array}{l}\text { Billieux, Van } \\
\text { Der Linden, } \\
\text { and } \\
\text { Rochat(2008) }\end{array}$ & $\begin{array}{c}\text { Problematic } \\
\text { Use }\end{array}$ & Literature \\
\hline $\begin{array}{l}\text { SMS Problem } \\
\text { Use Diagnostic } \\
\text { Questionnaire }\end{array}$ & SMS-PUDQ & $\begin{array}{c}\text { Rutland, } \\
\text { Sheets, and } \\
\text { Young(2007) }\end{array}$ & $\begin{array}{c}\text { Problematic } \\
\text { Use }\end{array}$ & Literature \\
\hline $\begin{array}{c}\text { Mobile } \\
\text { Addiction Test }\end{array}$ & MAT & $\begin{array}{l}\text { Martinotti et } \\
\text { al. (2011) }\end{array}$ & Addiction & Literature \\
\hline $\begin{array}{l}\text { Mobile Phone } \\
\text { Addiction } \\
\text { Index }\end{array}$ & MPAI & Leung (2007) & Addiction & Literature \\
\hline $\begin{array}{l}\text { Nomophobia } \\
\text { Questionnaire }\end{array}$ & NMP-Q & $\begin{array}{l}\text { Yildirim } \\
\text { (2014) }\end{array}$ & Nomophobia & $\begin{array}{c}\text { Literature } \\
\text { and } \\
\text { Exploratory }\end{array}$ \\
\hline
\end{tabular}

Despite the problematic use of Smartphone being very recent, certain psychometric scales were developed and validated to understand what constitutes this phenomenon. Most 
of the available scales were developed based on the analysis of literature investigating addiction problems with a focus on different perspectives including: Dependency, Addiction and Problematic (Bianchi et al., 2005; Yildirim, 2014). The dependency scales include the Questionnaire of Dependence of Mobile Phone (QDMP), Test of Mobile Phone Dependence (TMPD), Mobile Phone Dependence Questionnaire (MPDQ), and Perceived Dependence on the Mobile Phone (PDMP). Studies that focus on the use of Smartphones as a problem include Problematic Mobile Phone Use Questionnaire (PMPUQ), Mobile Phone Problem Use Scale (MPPUS), SMS Problem Use Questionnaire and Problematic Mobile Phone Use Scale (PMPUS). The other studies considered the phenomenon using addiction developed scales such as Mobile Addiction Test (MAT) and Mobile Phone Addiction Index (MPAI).Several of those tools were listed in Table 1, described in further detail in other studies (Yildirim, 2014).

Although those scales have different assessment criteria, most of those were Likert-type scales consisting of 20 to 100 items developed by the researchers. The tools used in such scales were designed and improved based on various definitions of mobile devices, behavioural addiction and dependency, and their major objective is assessing the problematic usage of mobile devices with criteria to assess behavioural addiction (Bianchi et al., 2005; Walsh et al., 2010). It is clear from the literature that no specific scale was developed to particularly assess Nomophobia, and most of those scales developed the assessment items based on criteria for the diagnosis of substance use or addiction as described in DSM-4 or DSM-5. This finding implies that the testing tools require samples to examine the psychometric properties of the measures and do not specifically measure Nomophobia. Two recent studies considered the development of Nomophobia-focused scales with a particular focus on Nomophobia symptoms and dimensions as a theoretical construct as reported in the related literature; these tools have also been validated using approved mixed research methods (King et al., 2014; Yildirim, 2014). Thus, this study considers 
using Nomophobia Questionnaire (NMP-Q) as the most recently developed and validated scale focused on the phenomenon (Yildirim, 2014).

\section{Empirical Research Methodology}

\section{Research Objectives}

This study investigates the prevalence and psychological symptoms of Nomophobia among university students in Saudi Arabia, particularly in the Faculties of Education, Arts and Humanities Colleges of King Abdulaziz University. This study will attempt to achieve the following objectives:

- identify the behavioural patterns of using Smartphone technologies among participants;

- assess the prevalence among participants of the following Nomophobia dimensions: Not Being Able to Communicate (NBAC), Losing Connectedness (LC), Access Information Disability (AID) and Giving up Convenience (GUC); and

- identify the psychological health factors (depression, anxiety and stress) affected by the behavioural patterns of using Smartphone technologies.

\section{Data Collection Instrument and Variables}

This study was a cross-sectional design with participants completing a self-report survey. The survey consisted of 7 parts. The first part assessed demographic information (gender, age $(<22$ and $>=22$ ), university year (freshmen, sophomore, junior and senior), and the degree (Bachelors and Masters). The second part asks participants about the average duration of Smartphone use by measuring the number of hours spent on Smartphones, the frequency and the duration of use. These indicators were summed to form a scale reflecting the average duration of Smartphones use. The third part asks about the frequency of participants' use (receiving and making) of calls, texts and emails. The frequency of use summed six items as an overall indicator of the Smartphone frequency of use. The fourth part asks about the activities of using the Smartphone (email, information seeking, awareness seeking, socialization, media, 
news and gaming). The fifth part asks the participants when they use their Smartphones (e.g., while eating food, when feeling bored, between classes, and during classes).

The sixth part measures participants' Depression, Anxiety and Stress Scales (DASS) using a 15-item self-report scale. The responses were provided using 5-point Likert scales ranging from 1 (strongly disagree) to 5 (strongly agree), which converted later to a 4-point Likert scale ranging from 0 to $3(0=$ Strongly Disagree and Disagree, $1=$ sometimes, $2=$ agree, $3=$ strongly agree). Responses to each subscale were aggregated and standardized using a Z-score formula to compare with the predetermined categories of the DASS, which separate normal, mild, moderate, severe and extremely severe levels of depression, anxiety and stress $(\alpha=0.002)$. The seventh part contains the Mobile Phone Involvement Questionnaire (MPIQ), which consists of 20 selfreport items categorized into four factors; Not being able to Communicate (NBAC) ( 6 items, $\alpha=0.90$ ), Losing Connectedness (LC) (5 items, $\alpha=0.93$ ), Access Information Disability (AID) (4 items, $\alpha=0.91$ ) and Giving up Convenience (GUC) (5 items, $\alpha=0.83$ ). Responses were provided using a 5-point Likert scale ranging from 1 (strongly disagree) to 5 (strongly agree), in which the higher the scale, will be the higher level of involvement. The Smartphone and smart devices involvement was calculated by averaging all factors $(\alpha=0.96)$.

\section{Results}

\section{Participants}

The initial sample consisted of 374 students. Among these, 335 participants were considered for our study after excluding the data from 39 incomplete surveys. Of the participants, $81.2 \%$ were females (272), and 18.8\% (63) were males. More than half of the participants were less than 24 years old, $53.7 \%$ (180); the remaining participants, 155 (46.3\%), were less than 24 years. Half of the participants were senior students $(169,50.4 \%) ; 84$ (25.1\%) were sophomores. In addition, 49(14.6\%) were juniors, and $33(9.9 \%)$ were freshmen. The vast majority of our sample 
was studying in an undergraduate program, $87.8 \%$ (294); the remaining was enrolled in a Masters program, $12.2 \%$ (41).

\section{Daily Behavioural Patterns of Use}

Duration of use: The results indicate that $6.6 \%$ use their devices for less than 2 hours, and $93.4 \%$ use their devices for more than 2 hours a day. Moreover, more than half (63.3\%) of our participants use their devices more than 4 hours per day. Of the participants, 3\% do not check their Smartphones regularly, and $61.2 \%$ check their phones more than 10 times per day. Furthermore, $57.9 \%$ check their phones every 30 minutes or less, and $88.8 \%$ reported that they have more than one application on their Smartphones. The average duration of use was 4.1 ( $\mathrm{SD}=1.07)$. The results also indicated that there is no significant difference in the duration of use average for both genders and age groups.

Frequency of use: The average sum for the daily frequency of Smartphone use was 8.15 ( $S D=3.55$, ranging from 5 to 30 ). The results show that males (Mean=10.43, SD=5.92) are more frequent users of Smartphones than females (Mean=7.62, $\mathrm{SD}=2.45)$ with $(\mathrm{t}=3.69$, $\mathrm{p}$-value $=0.000)$. The results provided similar results with regard to age; the older group participants $(>=22$ years) on average are more frequent users of Smartphones than the younger group participants ( $<22$ years), with an average of $8.72(\mathrm{SD}=3.86)$ versus $7.64 \quad(\mathrm{SD}=3.16)$, respectively, with $(\mathrm{t}=2.79$, $\mathrm{p}$-value $<0.01)$.

Purpose of use: The high volume and frequency of Smartphone use is explained by the purpose of use: $94 \%$ of our participants use it to visit social media networks, $89.3 \%$ use it to avoid boredom, $89 \%$ talk with family or friends, $86.9 \%$ seek information on the Internet, $779.1 \%$ text family or friends, $78.2 \%$ listen to music, $77 \%$ check email, $73.4 \%$ obtain news, $63.9 \%$ read educational material, $52.8 \%$ play games and $43.3 \%$ schedule meetings and events. The purposes of use were the same for males and females excluding purposes 3 and 10 (seek information and news). Males seek more information $(95.2 \%$ versus $84.9 \%$ ) and news (88.9\% versus $69.9 \%$ with $\chi^{\wedge 2}=9.50, \mathrm{p}<$ 
0.01) than females. Regarding the two age groups, purpose 3 alone was significantly different between the two age groups. Older students $(>=22)$ use Smartphones more for seeking information than younger students, $91.8 \%$ versus $52.5 \%$ with $\chi^{\wedge 2}=6.31, p<0.01$ ). Table 2 illustrates the Purpose of Use results.

Table 2. Purpose of use.

\begin{tabular}{|l|c|}
\hline \multicolumn{1}{|c|}{ Purpose of Use } & $\%$ \\
\hline Visiting Social Networks & 94.0 \\
\hline Killing free or extra time & 89.3 \\
\hline Calling family members and friends & 89.0 \\
\hline Searching for information on the Internet & 86.9 \\
\hline Sending SMS Messages to family members and friends & 79.1 \\
\hline Searching and downloading music tones & 78.2 \\
\hline Checking and sending email & 77.0 \\
\hline Searching for news online & 73.4 \\
\hline Reading and downloading educational materials & 63.9 \\
\hline Searching for and playing games online & 52.8 \\
\hline Making appointments and scheduling meetings & 43.3 \\
\hline
\end{tabular}

Context of use: More than $82 \%$ of our participants use their Smartphones in many contexts: $93.7 \%$ use it when they are alone, $89.3 \%$ between classes (break time), 89.3\% while waiting for someone or something, 89\% when they are bored, and $82.7 \%$ on public transportation. Of our participants, $68.4 \%$ use Smartphones while walking, $65.4 \%$ while watching TV or a movie, 52.8\% while hanging out with friends, approximately $48 \%$ while driving or during a class; in addition, the lowest percentage of our participants use it at the dinner table (40.9\%). Males and females are the same in all contexts of use except for contexts 3 and 10. Females use Smartphones more than males between classes, $91.9 \%$ versus $77.8 \%$ with $\left(\chi^{\wedge}=10.65, p<0.01\right)$. In addition, females tend to use Smartphones more than males 
while they are walking, $71.3 \%$ versus $55.6 \%$ with $\left(\chi^{\wedge 2}=5.88, p<\right.$ 0.05). In regards to age, context 1 alone was significantly different between the two age groups $(<22$ and $>=22)$. The younger group uses the Smartphone more than the older group, $47.5 \%$ versus $33.5 \%$ with $\chi^{\wedge 2}=6.69, \mathrm{p}<0.01$ ). Table 3 illustrates the Context of Use results.

Table 3. Context of use.

\begin{tabular}{|l|c|}
\hline \multicolumn{1}{|c|}{ Context of Use } & $\%$ \\
\hline When I am alone & 93.7 \\
\hline During breaks between lectures & 89.3 \\
\hline While I am waiting someone or something & 89.3 \\
\hline When I am bored & 89.0 \\
\hline In waiting or rest rooms & 88.1 \\
\hline While travelling on public transportation & 82.7 \\
\hline While I am walking to reach someplace or something & 68.4 \\
\hline While I am watching TV programs or movies & 65.4 \\
\hline While hanging out with friends & 52.4 \\
\hline While driving & 48.7 \\
\hline At a dinner table & 40.9 \\
\hline While talking to someone & 37.0 \\
\hline
\end{tabular}

\section{The Prevalence of Nomophobia Dimensions}

The aggregated Smartphone involvement average was 3.2 $(\mathrm{SD}=0.97)$, with subscale averages of $3.39(\mathrm{SD}=1.05), 2.92$ ( $S D=1.19), 3.31(S D=1.15)$ and 3.24(SD=1.02) for NABC, LC, AID and GUC, respectively. There was no significant difference in terms of Smartphone involvement between the two age groups $(<22,>=22)$. However, females were significantly more involved than males, with a mean of $3.3(\mathrm{SD}=0.93)$ versus $2.83(\mathrm{SD}=1.05)$ with $\mathrm{t}=3.54$, $\mathrm{p}$-value $<0.001$.

\section{Assessing DASS Variables}

Depression: The average depression score was 8.55 $(\mathrm{Z}=0.83)$ ( $\mathrm{SD}=3.41$, ranging from 1 to 17$)$, which indicates that the average participant experienced a "Mild" level of depression. The results indicate that females are significantly more 
depressed than males, with an average of $8.88(\mathrm{SD}=3.37)$ versus 7.11 ( $\mathrm{SD}=3.25)$ with a $(\mathrm{t}=0.79$, $\mathrm{p}$-value $<0.001)$. The results also showed that younger groups $(<22)$ are more depressed than older groups $(>=22)$, with an average of $8.97(\mathrm{SD}=3.34)$ versus $8.08(\mathrm{SD}=3.43)$ with $(\mathrm{t}=2.38$, $\mathrm{p}$-value $<0.05)$.

Anxiety: The average anxiety score was $5.96(\mathrm{Z}=-0.03)$ $(\mathrm{SD}=2.9$, ranging from 0 to 12 ), which indicates that the average participant experienced nearly a "Normal" level of anxiety. The gender and age groups showed no significant differences in terms of anxiety.

Stress: The average depression score was $6.55(Z=-1.90)$ ( $\mathrm{SD}=4.8$, ranging from 0 to 18 ), which indicates that the average participant experienced a "Normal" level of stress. The gender and age groups showed no significant differences in terms of stress.

\section{Correlation between Variables}

Table 4. Bivariate correlations for study variables

\begin{tabular}{|c|c|c|c|c|c|c|c|c|c|c|c|c|}
\hline Variable & 1 & 2 & 3 & 4 & 5 & 6 & 7 & 8 & 9 & 10 & 11 & 12 \\
\hline NBAC (1) & 1 & & & & & & & & & & & \\
\hline LC (2) & $.75^{* *}$ & 1 & & & & & & & & & & \\
\hline AID (3) & $.66^{* *}$ & $.62^{* *}$ & 1 & & & & & & & & & \\
\hline GUC (4) & $.73 * *$ & $.73 * *$ & $.72 * *$ & 1 & & & & & & & & \\
\hline $\begin{array}{l}\text { MPI_TOTAL } \\
\text { (5) }\end{array}$ & $.89 * *$ & $.89 * *$ & $.86^{* *}$ & $.89 * *$ & 1 & & & & & & & \\
\hline $\begin{array}{l}\text { FREQUENCY } \\
\text { OF USE(6) }\end{array}$ & -0.01 & -0.01 & $\begin{array}{l}- \\
0.05\end{array}$ & \begin{tabular}{|l|}
- \\
0.001
\end{tabular} & $\begin{array}{l}- \\
0.02\end{array}$ & 1 & & & & & & \\
\hline $\begin{array}{l}\text { DURATION } \\
\text { OF USE(7) }\end{array}$ & $.24^{* *}$ & $.17^{* *}$ & $.17^{* *}$ & $.28^{* *}$ & $.24^{* *}$ & 0.07 & 1 & & & & & \\
\hline $\begin{array}{l}\text { DEPRESSION } \\
\text { (8) }\end{array}$ & $.60 * *$ & $.57 * *$ & $.62 * *$ & $.63^{* *}$ & $.69 * *$ & .001 & $.21^{* *}$ & 1 & & & & \\
\hline ANXIETY (9) & $.56^{* *}$ & $.48^{* *}$ & $.54 * *$ & $.62 * *$ & $.62 * *$ & .06 & $.24^{* *}$ & $.64^{* *}$ & 1 & & & \\
\hline STRESS (10) & $.51^{* *}$ & $.56^{* *}$ & $.55^{* *}$ & $.57^{* *}$ & $.62^{* *}$ & .079 & $.17^{* *}$ & $.65^{* *}$ & $.56^{* *}$ & 1 & & \\
\hline $\begin{array}{l}\text { GENDER } \\
\text { (11) }\end{array}$ & $.118^{*}$ & $.18^{* *}$ & $.19 * *$ & $.18^{* *}$ & $.19 * *$ & $.31 * *$ & $.25^{* *}$ & $.20^{* *}$ & $.11 *$ & $.56 * *$ & 1 & \\
\hline AGE (12) & -0.04 & $\begin{array}{l}- \\
0.103\end{array}$ & $\begin{array}{l}- \\
0.09\end{array}$ & -0.1 & $\begin{array}{l}- \\
0.10\end{array}$ & $.13^{*}$ & $\begin{array}{l}- \\
0.01\end{array}$ & $\begin{array}{l}- \\
.16^{* *}\end{array}$ & $\begin{array}{l}- \\
0.05\end{array}$ & $.11^{*}$ & $\begin{array}{l}- \\
.41 * *\end{array}$ & 1 \\
\hline
\end{tabular}

** Correlation is significant at the 0.01 level, ${ }^{*}$ Correlation is significant at the 0.05 level 
As shown in Table 4, the correlations between the frequency of Smartphone use, Smartphone involvement scale and subscales, and psychological health factors (DASS) were not significant. However, the duration of use was significant for both Smartphone involvement and the psychological health factors. The highest correlation was between the duration of use and NBAC from the MPI factors and anxiety from the psychological health factors, with approximately the same correlation of 0.237 (p-value $<0.01$ ).

However, the psychological health factors (DASS) all correlated significantly ( $\mathrm{p}$-value $<0.01$ ) with the Smartphone involvement factors. The highest correlation was with depression, and the same correlation occurred with anxiety and stress $(r=0.633,0.622$ with $p$-value $<0.01)$, respectively. In terms of the correlation of MPI factors with psychological health factors, the highest correlated factors was GUC with all psychological health factors, followed by AID, and approximately the same correlation strength was found for LC and NBAC. In addition, the highest correlation between MPI factors with psychological health factors was depression. Age was solely positively correlated with frequency of use $(r=0.13$ with $p$-value $<0.05)$ and negatively correlated with depression ( $r=-0.16$ with p-value <0.01). Gender was correlated positively and significantly with all MPI factors and psychological health factors. This finding means that females are more involved with Smartphone use and duration and develop more psychological health factors, particularly stress $(\mathrm{r}=0.56$ with $\mathrm{p}$-value $<0.01$ ). Frequency of use was correlated positively with age ( $>=22$ users are more frequent users of Smartphones than the younger, $<22$ users; $r=0.125$, with $p$-value $<0.05$ ) and negatively with gender ( $r=-0.31$ with $p$-value $<0.01$ ).

\section{Discussion}

Consistent with earlier research, this study showed significant associations between psychological symptoms 
(depression, anxiety and stress) and the manner in which a person uses their Smart-devices; in particular, there was a significant association between these variables and the duration of use (Harwood et al., 2014).

\section{Assessing the Model of Fit}

Structural equation modelling was used to test the hypothesized relations between the predictor variables and the psychological health factors (DASS). Frequency of use, duration of use, Smartphone involvement, age and gender, were specified as the direct predictors of psychological health factors. Additionally, all dependent and independent variables were allowed to co-vary; thus, the cause and effect relation related to the psychological health factors can be inferred. The general fit of the model was good based on goodness of fit indicators $\left(\chi^{\wedge 2}=3.44, \quad \mathrm{df}=30, \quad \mathrm{p}\right.$-value $=0.000, \quad$ GFI $=0.963 ; \quad$ AGFI $=0.919$; $\mathrm{CFI}=0.976$; $\mathrm{AIC}=144.3$; RMSEA=0.065).

According to the results of the structural regression analysis model, MPI has a direct and positive effect on psychological health factors with a standardized regression (path) co-efficient $(\beta=0.89$ with $p$-value $=0.001)$. Gender was also positively associated with LC and AID $(\beta=0.078,0.079$ with pvalue $<0.05$ ). Frequency of use was not significant with any of the endogenous factors when tested in the full model, despite the significant bivariate correlation coefficient. However, the duration of use was significantly and positively associated with NBAC $(\beta=0.122$ with $p$-value $<0.001)$ and GUC $(\beta=0.152$ with $p$ value $<0.001$ ) from the MPI factors, and it was directly associated with all psychological health factors; anxiety $(\beta=0.144$ with $p$-value $<0.05)$; depression $(\beta=0.104$ with $p$-value $<0.05)$; and stress $(\beta=0.098$ with $p$-value $<0.05)$. The predictors explained $79 \%$ of the variation in psychological health factors (DASS). Figure 2 illustrates the standardized coefficients for the final model. 




Figure 2: The standardized coefficients for the final model ${ }^{\wedge}$

^ Figure 2.Standardized coefficients for the final model with solely significant paths DASS using MPI, frequency of use, duration of use, gender and age. Smartphone involvement $(\mathrm{N}=292)$. All exogenous variables were permitted to co-vary, showing significant correlation coefficients. Where: ${ }^{*} \mathrm{p}<.05,{ }^{* *} \mathrm{p}$ $<.01, * * * \mathrm{p}<.001$.

\section{Educational Environment Implications}

The university environment is an ideal place to develop social relationships, interact with others, and exchange knowledge. This environment can be viewed as an open social system and environment consisting of individuals and groups of students who have learning responsibilities and goals. However, this open environment is also considered a socially tense system that involves various educational, environmental, social, cultural or psychological forces and factors that can facilitate or restrain a given educational outcome. This study showed that Nomophobia is one of those critical factors that can restrain the ultimate educational outcome; therefore, it should be addressed by developing awareness of the patterns of use of Smart-devices in 
both the classroom and the larger university environment. Educational counsellors and psychologists need to develop programs to educate students on how, when, why and where they can use their Smartphones. Instructors with the support of educational administration need also to regulate the use Smartphones in and outside of classrooms through applying developed policies and rules.

\section{Educational Performance Implications}

The findings illustrated that universities are systems that, although designed to promote learning, can encounter forces that make their tasks difficult or, in certain cases, impossible to achieve. This outcome here is in parallel with the findings of prior research that focuses on students' subjective experience of university settings and their psychological environment; then, it considers the classroom as a dynamic tension system in which multiple forces exist and interact(Garcia, 2011). In sum, both socio-technological factors and psychological factors have a large impact on educational performance. Mixtures of those factors may act as powerful restraining forces, preventing positive forces in both the students and the university environment from asserting their full impact on behavior, and consequently on educational performance. Further, as the pathological fear caused by Nomophobia may involve discomfort, anxiety, nervousness, anguish or other psychological symptoms, educational performance will be affected in a way or another. Therefore, counsellors and psychologists within educational environments are advised to consider such issues while dealing with students, and need to establish campaigns explaining the affect of Nomophobia.

\section{Potential Treatments and Recommendations}

Earlier studies on Nomophobia in particular are limited, and randomized trials in the area are currently lacking. Therefore, a small number of scholars may accept empirical treatment methods. An earlier study suggested that treatments primarily may consist of a combination of psychotherapy and certain pharmacological interventions and cognitive behavioural 
psychotherapy. The cognitive behavioural psychotherapy is a brief therapy that includes structured sessions and specific objectives in which the both the patient and the therapist have active roles. The intention is to link catastrophic interpretations of events and to condition the patient's fears, sensory sensations, and avoidance behaviours. The patients are then taught distraction strategies and are strongly encouraged to have faceto-face conversations and relationships, engage in a sport and breathe deeply, consequently reducing the time spent with a Smartphone and online connections(Bragazzi \& Del Puente, 2014). Therefore, it would be beneficial to direct students identified with Nomophobia to counselors to attain a more appropriate use of Smart-devices.

\section{Study Limitations}

The study was a cross-sectional survey study conducted at few universities on students; therefore, the scales used may not provide a definitive diagnosis for a larger population. Another limitation of this study is that the data were derived from volunteers who use a Smartphones; therefore, the findings may not be generalized to non-volunteers.

\section{Conclusions}

The introduction of modern ICT tools for personal use, such as Smartphones, smart-devices, personal computers and tablets, has shaped our daily and social lives, causing changes in humans' habits and behaviours, in both a positive and a negative manner. It is clear that technology for social media and networking and platforms for smart-devices enables conducting professional and social activities more quickly and with more efficiency. However, Smartphones and smart-devices, as reported by many studies, can have a dangerous impact on human health and educational performance. Being deeply involved in Smartphone use has, for example, been reported to result in the development of psychological phobias and fear. In this study, the prevalence and symptoms of Nomophobia among university students in Saudi Arabia was investigated. Based on real data collection and analysis, it was determined that Smartphone involvement among 
university students can cause a major health problem, which consequently may impact academic achievement where by the severity of depression, stress and anxiety may increase. It would be beneficial to guide students identified with Nomophobia to specialist counselling to obtain more accurate diagnosis and treatment. However, further research is needed to conduct an indepth study of the psychological and social aspects of Nomophobia and to develop standardized and operational definitions of this new phenomenon.

\section{References}

Abdullah, Z., Zulkifly, H. Z., Saaid, S. A., \& Din, F. (2012). Peers' validation, mobile phone involvement and family cohesion among secondary school children. In The Asian conference on media and mass communication 2012: Official conference proceedings 2012. Malaysia: Universiti Teknologi MARA.

Bianchi, A., Phillips, J. G., \& Phillips, J. G. (2005). Psychological predictors of problem mobile phone use. Cyberpsychology \& Behavior, 8(1), 39-51.

Billieux, J., Van Der Linden, M., \& Rochat, L. (2008). The role of of impulsivity in actual and problematic us of the mobile phone. Applied Cognitive Psychology, 22, 1195-1210.

Bivin, J., Mathew, P., Thulasi, P. C., \& Philip, J. (2013). Nomophobia - Do we really need to worry about? A cross sectional study on nomophobia severity among male under graduate students of health sciences. Reviews of Progress, 1 , 1-5.

Bragazzi, N., \& Del Puente, G. (2014). A proposal for including nomophobia in the new DSM-V. Psychology Research and Behavior Management, 7, 155-160.

Byun, Y., Ha, M., Kwon, H., Choi, K., Burm, E., Choi, Y., . . Kim, N. (2013). Epidemiological characteristics of mobile phone ownership and use in Korean children and adolescents. Environmental Health and Toxicology, 28, e2013018.

Chóliz, M. (2012). Mobile-phone addiction in adolescence: The test of mobile phone dependence (TMD). Progress in Health Sciences, 2(1), 33-44. 
Choy, Y., Fyer, A. J., \& Lipsitz, J. D. (2007). Treatment of specific phobia in adults. Clinical Psychology Review, 27(3), 266286.

Dickson, D. (2012). Physiological and psychological consequences of forced mobile phone abstention. Retrieved from https://digital.library.txstate.edu/handle/10877/4237.

Dixit, S., Shukla, H., Bhagwat, A., Bindal, A., Goyal, A., Zaidi, A., \& Shrivastava, A. (2010). A study to evaluate mobile phone dependence among students of a medical college and associated hospital of central India. Indian Journal of Community Medicine, 35(2), 339-341.

Forgays, D. K., Hyman, I., \& Schreiber, J. (2014). Texting everywhere for everything: Gender and age differences in cell phone etiquette and use. Computers in Human Behavior, $31,314-321$.

Garcia, J. (2011). Social psychological perspective on educational intervention. Stanford, CT: Stanford University.

Harwood, J., Dooley, J. J., Scott, A. J., \& Joiner, R. (2014). Constantly connected - The effects of smart-devices on mental health. Computers in Human Behavior, 34, 267-272.

International Telecommunication Union. (2014). The world in 2014 - ICT facts and figures. Retrieved from http:// www.itu.int/en/ITU-

D/Statistics/Documents/facts/ICTFactsFigures2014-e.pdf.

King, A. L. S., Valença, A. M., \& Nardi, A. E. (2010). Nomophobia:

The mobile phone in panic disorder with agoraphobia. Cognitive and Behavioral Neurology, 23(1), 52-54.

King, A. L. S., Valença, A. M., Silva, A. C. O., Baczynski, T., Carvalho, M. R., \& Nardi, A. E. (2013). Nomophobia: Dependency on virtual environments or social phobia? Computers in Human Behavior, 29(1), 140-144.

King, A. L. S., Valença, A. M., Silva, A. C., Sancassiani, F., Machado, S., \& Nardi, A. E. (2014). "Nomophobia": Impact of cell phone use interfering with symptoms and emotions of individuals with panic disorder compared with a control group. Clinical Practice and Epidemiology in Mental Health, $10,28-35$. 
King, D. L., \& Delfabbro, P. H. 2013. Issues for DSM-5: Videogaming disorder. The Australian and New Zealand Journal of Psychiatry, 47(1), 20-22.

Krajewska-Kułak, E., Kułak, W., Stryzhak, A., Szpakow, A., Prokopowicz, W., \& Marcinkowski, J.T. (2012). Problematic mobile phone using among the Polish and Belarusian University students, a comparative study. Progress in Health Sciences, 2(1), 45-50.

Lee, S. Y. (2014). Examining the factors that influence early adopters' smartphone adoption: The case of college students. Telematics and Informatics, 31(2), 308-318.

Leung, L. (2007). Leisure boredom, Sensation seeking, selfesteem, addiction symptoms and patterns of mobile phone use. In E. Konjin (Ed.), Mediated interpersonal communication (pp. 359-398). New York, NY: Routledge.

Lu, X., Watanabe, J., Liu, Q., Uji, M., Shono, M., \& Kitamura, T. (2011). Internet and mobile phone text-messaging dependency: Factor structure and correlation with dysphoric mood among Japanese adults. Computers in Human Behavior, 27(5), 1702-1709.

Martinotti, G., Villella, C., Di Thiene, D., Di Nicola, M., Bria, P., Conte, G., ... La Torre, G. (2011). Problematic mobile phone use in adolescence: A cross-sectional study. Journal of Public Health, 19, 545-551.

Merlo, L. J., Stone, A. M., \& Bibbey, A. (2013). Measuring problematic mobile phone use: Development and preliminary psychometric properties of the PUMP scale. Journal of Addiction, 2013, 912807.

Nash, A., \& Fitzpatrick, J. M. (2015). Views and experiences of nurses and health-care assistants in nursing care homes about the gold standards framework. International Journal of Palliative Nursing, 21(1), 35-41.

Pew Research Center. (2015). Mobile technology fact sheet. Retrieved from http://www.pewinternet.org/fact-sheets/ mobile-technology-fact-sheet/.

Rutland, J. B., Sheets, T., \& Young, T. (2007). Development of a scale to measure problem use of short message service: The 
SMS problem use diagnostic questionnaire. Cyberpsychology \& Behavior, 10(6), 841-843.

Salehan, M., \& Negahban, A. (2013). Social networking on smartphones: When mobile phones become addictive. Computers in Human Behavior, 29(6), 2632-2639.

Securenvoy. (2012). 66\% of the population suffer from Nomophobia the fear of being without their phone. Retrieved from http://www.securenvoy.com/blog/2012/02/16/66of-the-population-suffer-from-nomophobia-the-fear-ofbeing-without-their-phone/.

Sharma, N., Sharma, P., Sharma, N., \& Wavare, R. (2015). Rising concern of nomophobia amongst Indian medical students. International Journal of Research in Medical Sciences, 3(3), 705.

Starcevic, V. (2010). Problematic internet use: A distinct disorder, a manifestation of an underlying psychopathology, or a troublesome behaviour? World Psychiatry, 9(2), 92-93.

Szasz, T. (2005). What counts as disease? The gold standard of disease versus the Fiat standard of diagnosis. The Independent Review, X, 325-336.

Taouk, M., Lovibond, P. F., \& Laube, R. (2001). Psychometric properties of an Arabic version of the Depression Anxiety Stress Scales (DASS21).

Thomée, S., Härenstam, A., \& Hagberg, M. (2011). Mobile phone use and stress, sleep disturbances, and symptoms of depression among young adults - A prospective cohort study. BMC Public Health,11, 66.

Toda, M., Monden, K., Kubo, K., \& Morimoto, K. (2006). Mobile phone dependence and health-related lifestyle of University students. Social Behavior and Personality, 34(10), 12771284.

Walsh, S. P. (2009). A psychosocial approach to understanding young Australians' mobile phone behaviour (Doctoral dissertation). Queensland University of Technology, Brisbane, Australia. 
Walsh, S., White, K. M., \& Young, R. M. (2010). Needing to connect: The effect of self and others on young people's involvement with their mobile phones. Australian Journal of Psychology, 62(4), 194-203.

Yen, C., Tang, T., Yen, J., Lin, H., Huang, C., Liu, S., \& Ko, C. (2009). Symptoms of problematic cellular phone use, functional impairment and its association with depression among adolescents in Southern Taiwan. Journal of Adolescence, 32(4), 863-873.

Yen, J., Ko, C., Yen, C., Chen, S., Chung, W., \& Chen, C. (2008). Psychiatric symptoms in adolescents with internet addiction: Comparison with substance use. Psychiatry and Clinical Neurosciences, 62(1), 9-16.

Yildirim, C. (2014). Exploring the dimensions of nomophobia: Developing and validating a questionnaire using mixed methods research (Doctoral dissertation). Iowa State University, Ames, IA. 